European Journal of STEM Education, 1:3 (2016), 58

ISSN: $2468-4368$

\title{
A Comparative Study of Geometry in Elementary School Mathematics Textbooks from Five Countries
}

Tzu-Ling Wang ${ }^{1}$, Der-Ching Yang²*

${ }^{1}$ National Chiayi University, TAIWAN

${ }^{2}$ National Hsinchu University of Education. TAIWAN

*Corresponding Author: dcyang@mail.ncyu.edu.tw

Citation: Wang, T.L. and Yang, D.C. (2016) A Comparative Study of Geometry in Elementary School Mathematics Textbooks from Five Countries, European Journal of STEM Education, 1:3 (2016), 58.

doi: http://dx.doi.org/10.20897/lectito.201658

Received: May 15, 2016; Accepted: June 23, 2016; Published: December 28, 2016

\begin{abstract}
The purposes of this study were to compare the differences in the use of geometry in elementary school mathematics textbooks among Finland, Mainland China, Singapore, Taiwan, and the USA and to investigate the relationships between the design of the textbooks and students' performance on large-scale tests such as TIMSS-4 geometry, TIMSS-8 geometry, and PISA space and shape. The content analysis method was used to collect data, and then chi-square tests and correlation analyses were used to analyze data. The results showed that there were significant differences in representation form, problem type, and question format among these mathematics textbooks from the five countries. Moreover, the strength of the positive relationships between visual form (combined form) and students' performance on TIMSS-4 geometry, TIMSS-8 geometry, and PISA space and shape decreases as students advance to higher grades, whereas increasing strength of correlations as students get older is found between contextual problems and students' performance on the three large-scale tests.
\end{abstract}

Keywords: elementary school mathematics textbook, geometry, representation form, problem type, question format

\section{INTRODUCTION}

Many studies have focused on the comparison of mathematics curriculum and mathematics textbooks (Baker, Knipe, Cummings, Blair, \& Gamson, 2010; Cai, 2008; Cai \& Ni, 2011; Fan, Zhu, \& Miao, 2013; Reys, Reys, \& Rubenstein, 2010; Schoen, Ziebarth, Hirsch, \& BrckaLorenz, 2010; Usiskin \& Willmore, 2008; Zhu \& Fan, 2006). Baker et al. (2010) pointed out that mathematics textbooks can be regarded as the most accountable and important historical proof for the development of mathematics curriculum, research process, and the whole mathematics education history, which can help us realize the changes in a country's mathematics education. In addition, much research has shown that mathematics textbooks play a key role in the process of students' learning and teachers' teaching (Cai, 2008; Cai \& Ni, 2011; Chavez, 2003; Fan et al., 2013; Gonzales et al., 2004; Reys et al., 2010; Stein, Remillard, \& Smith, 2007). The quality of textbooks influences students' learning outcomes and mathematics achievement as well as teachers' teaching efficiency (Floden, 2002; Reys \& Reys, 2006; Stein et al., 2007; Törnroos, 2004). This highlights the importance of mathematics textbooks in mathematics learning and teaching.

Geometry has been considered a key topic in school mathematics classes (Finnish National Board of Education, 2004; Ministry of Education in Taiwan, 2008; National Council of Teachers of Mathematics [NCTM], 2000). For example, NCTM (2000) claimed that geometry can help people depict the world in a systematic way. In Taiwan, the Ministry of Education (2008) strongly emphasizes the importance of geometry in school mathematics 
curriculum. In fact, geometry not only plays an important role in mathematics but also highly affects students' mathematics learning (Atiyah, 2001).

During the past two decades, many textbook studies have focused on algebra or fraction, but few textbook studies have focused on geometry currently, especially in international and comparative textbook studies. Due to the importance of textbook content, many mathematics educators claim that we can observe the advantages and disadvantages of textbooks from different countries by conducting textbook analyses, which can then be used to revise our textbooks in the future (Cai, 2008; Hiebert et al., 2003; Hong \& Choi, 2014; Stigler \& Hiebert, 2004). Based on the aforementioned motivations, the purposes of this study were to compare the differences in the use of geometry in elementary school mathematics textbooks among Finland, Mainland China, Singapore, Taiwan, and the USA and to investigate the relationships between the design of textbooks and students' performance on largescale tests such as TIMSS-4 geometry, TIMSS- 8 geometry, and PISA space and shape. The research questions are as follows:

1. Are there any differences in representation forms (symbolic form, verbal form, visual form, and combined form) of geometry among the five mathematics textbooks?

2. Are there any differences in problem types (contextual problem, non-contextual problem) of geometry among the five mathematics textbooks?

3. Are there any differences in question formats (open-ended question, close-ended question) of geometry among the five mathematics textbooks?

4. What are the relationships between the scores of TIMSS- 4 geometry, TIMSS- 8 geometry, PISA space and shape and the frequencies of representation form, problem type, and question format?

\section{BACKGROUND}

Previous studies have shown extreme differences in mathematics content and design used in textbooks from different countries (Author et al., 2010; Fan, 2013; Schmidt, 2004; Zhu \& Fan, 2006). For example, although Asian countries such as Japan, Singapore, and Taiwan follow a national curriculum guideline, their textbooks still differ from each other. However, American textbooks do not have a national curriculum to follow (Schmidt, 2004). Reys, Reys, and Chavez (2004) discovered that American first grade mathematics textbooks usually consist of as many as 800 pages; on the contrary, Japanese and Taiwanese first grade mathematics textbooks include only one quarter of the pages of American counterparts, indicating that a large discrepancy exists in mathematics textbooks. According to the reports of the TIMSS and PISA tests, this kind of discrepancy can influence the performance in mathematics of students from different countries (Author et al., 2010; Fan, 2013; Schmidt, 2004; Zhu \& Fan, 2006). Previous studies have pointed out that mathematics textbooks can affect students' opportunity to learn directly; in other words, the quality of textbooks can influence how students learn mathematics (Cai, 2008; Cai \& Ni, 2011; Fan, 2013; Gonzales et al., 2004; Organization for Economic Co-operation and Development [OECD], 2013; Schmidt, 2004; Schmidt et al., 2001; Stein et al., 2007; Tarr, Chavez, Reys, \& Reys, 2006).

Author et al. (2010) compared the differences in fraction for fifth and sixth grades among Taiwan's Kang Hsuan textbooks (KH), Singapore's My Pals Are Here Maths (MPHM), and America's Mathematics in Context (MiC). The results revealed two major differences in the textbooks from these three countries. The first was that over $90 \%$ of MiC consisted of contextual problems, whereas only $55 \%$ of Taiwan $\mathrm{KH}$ and $48 \%$ of Singapore MPHM were contextual problems. Another difference is that American MiC highly stresses conceptual knowledge (about $76 \%$ ); however, Taiwan KH and Singapore MPHM have one-third of the problems focusing on the development of conceptual knowledge. A second difference is that Singapore MPHM placed fraction in fifth grade and stresses proportion in sixth grade. On the contrary, Taiwan $\mathrm{KH}$ and American MiC finished the whole fraction lessons in sixth grade.

Zhu and Fan (2006) compared problem representation in mathematics textbooks of Mainland China with their American counterparts. The results showed that American middle grade mathematics textbooks had high percentages of non-routine problems, non-traditional problems, open problems, application problems, and failingto-meet-conditions problems. On the contrary, Mainland China had more multi-step problems, thus the percentage of these types of challenging problems was higher in textbooks from Mainland China. Stein et al. (2007) compared two American mathematics textbooks and found that presentational order, method, and organization of the textbook content were different from each other. Presentational order and organization of textbooks can influence students' learning opportunities.

Many studies pointed out that the textbook is one of the major factors that influences students' learning (Cai \& Ni, 2011; Cai, Wang, Moyer, Wang, \& Nie, 2011; Fan, 2013; Schmidt et al., 2005). Reys et al. (2004) further claimed that problem types and presentation of the materials in the mathematics textbook are important factors that affect mathematics teaching and learning. Many studies suggested that multiple representations should be appropriately integrated into the mathematics classroom to enhance students' conceptual understanding (Author 
et al., 2004; Cramer, Post, \& delMas, 2002; NCTM, 2000; Rittle-Johnson \& Koedinger, 2005; Sood \& Jitendra, 2007). In addition, some studies suggested that visual forms should play an important role in mathematics teaching and learning (Bishop, 1991; Brenner, Herman, Ho, \& Zimmer, 1999; NCTM, 2000; River, 2010; Zimmermann \& Cunningham, 1991). Other studies pointed out that visual forms can help students construct geometrical concepts and facilitate students' visualizations of geometrical objects (Arcavi, 2003; David \& Tomaz, 2012; Presmeg, 2006).

Additionally, some researchers have argued that mathematics learning should connect to real-world contexts. That is, real-world mathematics activities should be integrated into the classroom to enable students to better understand mathematics (Author, 2006; NCTM, 2000; Sood \& Jitendra, 2007). Many studies found that increasing the number of real-world problems and applications in mathematics activities can help to diversify problems in mathematics textbooks. These kinds of mathematics activities can create a learning environment that helps students develop higher-level thinking and understanding (Author et al., 2010; Gu, Huang, \& Marton, 2004; Griffin, 2004; Griffin \& Jitendra, 2009; Van De Walle, 2007).

\section{METHOD}

\section{Selection of Textbooks}

Kang Hsuan (KH) elementary school mathematics textbooks have about a 38\% market share in Taiwan (Kang Hsuan Educational Publishing Group, 2009) and are the most commonly used elementary school mathematics textbook series. There are eight or nine units for each textbook, a total of 115 units in the Kang Hsuan series for grades 1-6, among which 21 units deal with the topic of geometry.

Everyday Mathematics (EM), a set of 1st-6th grade mathematics textbooks, was created by the research institution of the University of Chicago based on the standards of NCTM (National Council of Teachers of Mathematics, 1989, 2000). EM is one of three sets of standards-based elementary mathematics textbooks and it is also the most representative elementary school textbook in the USA with the highest market share (15.9\%) in the American elementary school textbook market (Reys \& Reys, 2006). The Everyday Mathematics series includes 38 units, with 6 units devoted to geometry.

Laskutaito mathematics textbooks, a set of 1st-6th grade mathematics textbooks, were published in 2004 by Finland Werner Söderström Corporation (WSOY) (Rikala, Sintonen, Uus- Leponiemi, Ilmavirta, \& Sieppe, 2006) and are based on the core mathematics curriculum development of Finland. Laskutaito has the highest proportion of the market share (70-80\%) among Finland's elementary school mathematics textbooks (Chen, 2008). There are 54 units in Laskutai mathematics textbooks for grades 1-6, and 6 units are devoted to geometry.

My Pals Are Here! Maths (MPHM) in Singapore is a set of 1st-6th grade mathematics textbooks edited by Fong, Ramakrishnan, and Gan (2005) under an agreement with the Ministry of Education in Singapore (2001). The market share of MPHM is about 60\% in elementary schools (Author et al., 2010). The MPHM series includes 93 units, 21 of which deal with the topic of geometry.

Mathematics textbooks in China were edited by elementary school mathematics educational experts, university professors, special teachers, and educational researchers. A set of textbooks were edited based on the current Chinese nine-year compulsory educational research. These kinds of textbooks have the highest proportion of the market share (40-50\%) among Chinese elementary school mathematics textbooks (Ji, 2004; Ma \&Tan, 2008). Such textbook series include 93 units for grades 1-6, with 18 units devoted to geometry.

\section{Analytical Framework}

The problems and exercises in the student textbooks were counted to determine the total number of geometrical items. The following is an example item:

Example 1: Who sees the object from this viewpoint?

Since there are four blanks for filling in answers, this was counted as four problems.

To answer the first research question, representation forms used in the geometry problems in the student textbooks were classified as symbolic form, verbal form, visual form, and combined form based on the study of Zhu and Fan (2006). If a geometry problem included only mathematical expressions, then the problem was coded as symbolic form. For example, "Which of the following items can form a triangle? (1) $4 \mathrm{~cm}, 3 \mathrm{~cm}, 8 \mathrm{~cm}$; (2) $3 \mathrm{~cm}$, $3 \mathrm{~cm}, 3 \mathrm{~cm}$; (3) $5 \mathrm{~cm}, 8 \mathrm{~cm}, 16 \mathrm{~cm}$ ?" (From KH 5A, p. 48). If a problem was presented in verbal form only, then the problem was coded as verbal form. For example, "Jane draws a community plan with a ratio 1:2000. There is a square park in the community plan. The real length and width of this square park are $1 \mathrm{~km}$ and $0.8 \mathrm{~km}$. What are the length and width of the square park of the community plan?" (From KH 6A, p. 128). If a problem was presented using figures, pictures, graphs, tables, and so on, then it was coded as visual form. For example, "Who can see the object from this viewpoint?" (see Figure 1). If two or more of the above representation forms were used in a problem, then it was coded as combined form. Figure 2 is an example item: 


\section{Who sees the object from this viewpoint?}

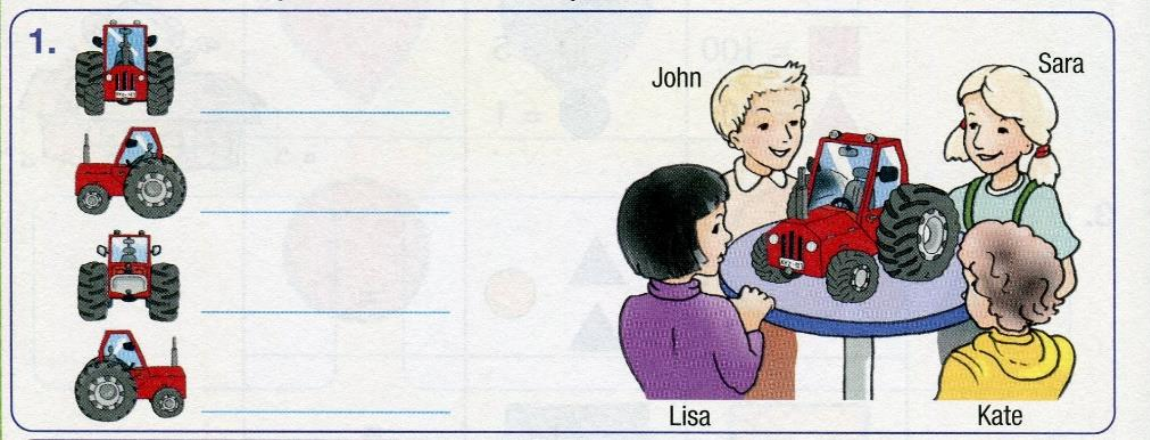

Figure 1. Example of counting problems and visual form from Laskutaito textbooks. Note. From Laskutaito 2B, p. 44.

64.

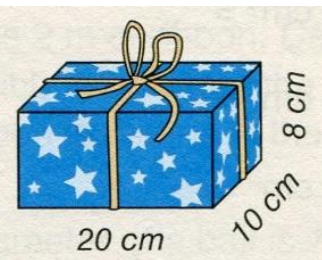

Shelly is wrapping a present like the one in the picture. $50 \mathrm{~cm}$ of ribbon is put aside for the decorative bow. How much ribbon is needed, in total?

Figure 2. Example of combined form from Laskutaito textbooks. Note. From Laskutaito 6A, p. 81.

To answer the second research question, problem types of the geometry problems in the student textbooks were classified as contextual and non-contextual problems (Author et al., 2010; Hiebert et al., 2003). If a problem was grounded in a real-world context, then it was coded as a contextual problem. If a problem was grounded in symbols in the language of mathematics, then it was coded as a non-contextual problem (Author et al., 2010; Hiebert et al., 2003). For example, "Which of the following items can form a triangle? (1) $4 \mathrm{~cm}, 3 \mathrm{~cm}, 8 \mathrm{~cm}$; (2) 3 $\mathrm{cm}, 3 \mathrm{~cm}, 3 \mathrm{~cm}$; (3) $5 \mathrm{~cm}, 8 \mathrm{~cm}, 16 \mathrm{~cm}$ ?” (From KH 5A, p. 48).

To answer the third research question, question formats of the geometry questions in the student textbooks were classified as open-ended and close-ended questions (Zhu \& Fan, 2006). An open-ended question is defined as a question with many correct answers (Zhu \& Fan, 2006). A close-ended question is defined as a question with only one correct answer (Zhu \& Fan, 2006).

To answer the fourth research question, the scores of TIMSS- 4 geometry, TIMSS-8 geometry, PISA space and shape from the reports of TIMSS 2011 test (Mullis, Martin, Foy, \& Arora, 2012) and PISA 2012 test (OECD, 2013) and the frequencies of representation form, problem type, and question format from elementary school mathematic textbooks were used in the present study.

\section{Inter-Rater Reliability}

In the present study, one mathematics educator and two graduate students served as raters for coding data. Based upon the coding framework, the raters independently coded the problems in the student textbooks. The inter-rater reliability coefficient for the raters was found to be 0.94 . 


\section{RESULTS}

\section{Differences in representation forms of geometry among the five mathematics textbooks}

The chi-square test for independence was used to evaluate whether representation form was related to country. In Table 1, the chi-square test showed that there was a significant association between representation form and country $((\mathrm{df}=12)=400.15, \mathrm{p}<0.001)$. This means that the percentages of representation forms in the textbooks from the five countries are significantly different from one another. A comparison of the representation forms and the four sets of percentages for each of the five countries shows that Mainland China had the highest percentage of symbolic form $(z=5.9)$ and highest percentage of verbal form among all countries; Finland $(z=5.8)$ had the highest percentage of visual form, and Singapore $(z=11.2)$ had the highest percentage of combined form.

Table 1. Cross-tabulation of representation form and country with adjusted residuals

\begin{tabular}{|c|c|c|c|c|c|c|}
\hline \multirow{2}{*}{ Representation form } & \multicolumn{6}{|c|}{ Country } \\
\hline & Finland & Mainland & Singapore & Taiwan & USA & Total \\
\hline Symbolic form & 13 & 31 & 59 & 3 & 1 & 107 \\
\hline (Percentage) & $(12.1 \%)$ & $(29.0 \%)$ & $(55.1 \%)$ & $(2.8 \%)$ & $(0.9 \%)$ & $(100 \%)$ \\
\hline (Adjusted residual) & $(-3.3)$ & $(5.9)$ & $(5.1)$ & $(-4.5)$ & $(-3.2)$ & \\
\hline Verbal form & 162 & 171 & 155 & 211 & 131 & 830 \\
\hline (Percentage) & $(19.5 \%)$ & $(20.6 \%)$ & $(18.7 \%)$ & $(25.4 \%)$ & $(15.8 \%)$ & $(100 \%)$ \\
\hline (Adjusted residual) & $(-4.9)$ & $(9.6)$ & $(-9.4)$ & $(4.4)$ & $(5.7)$ & \\
\hline Visual form & 573 & 206 & 536 & 407 & 157 & 1879 \\
\hline (Percentage) & $(30.5 \%)$ & $(11.0 \%)$ & $(28.5 \%)$ & $(21.7 \%)$ & $(8.4 \%)$ & $(100 \%)$ \\
\hline (Adjusted residual) & $(5.8)$ & $(-0.4)$ & $(-4.7)$ & $(2.4)$ & $(-3.9)$ & \\
\hline Combined form & 351 & 62 & 606 & 219 & 147 & 1385 \\
\hline (Percentage) & $(25.3 \%)$ & $(4.5 \%)$ & $(43.8 \%)$ & $(15.8 \%)$ & $(10.6 \%)$ & $(100 \%)$ \\
\hline (Adjusted residual) & $(-0.8)$ & $(-9.7)$ & $(11.2)$ & $(-4.8)$ & $(0.4)$ & \\
\hline Total & 1099 & 470 & 1356 & 840 & 436 & 4201 \\
\hline (Percentage) & $(26.2 \%)$ & $(11.2 \%)$ & $(32.3 \%)$ & $(20.0 \%)$ & $(10.4 \%)$ & $(100 \%)$ \\
\hline
\end{tabular}

\section{Differences in problem types of geometry among the five mathematics textbooks}

The chi-square test of independence was used to explore whether there is a relationship between problem type and country. The Pearson chi-square value is statistically significant, $(\mathrm{df}=4)=405.72, \mathrm{p}<0.001$. This means that the percentage for the two problem types varied as a function of country. Looking at Table 2, it can be seen that Mainland China and Taiwan had the higher percentages of contextual problems ( $z=16.9$ and $z=5.4$, respectively); on the contrary, Singapore and the USA had higher percentages of non-contextual problems $(z=12.5$ and $z=$ 5.1, respectively).

Table 2. Cross-tabulation of problem type and country with adjusted residuals

\begin{tabular}{|c|c|c|c|c|c|c|}
\hline \multirow{2}{*}{ Problem type } & \multicolumn{6}{|c|}{ Country } \\
\hline & Finland & Mainland & Singapore & Taiwan & USA & Total \\
\hline Contextual problem & 167 & 197 & 72 & 181 & 31 & 648 \\
\hline (Percentage) & $(25.8 \%)$ & $(30.4 \%)$ & $(11.1 \%)$ & $(27.9 \%)$ & $(4.8 \%)$ & $(100 \%)$ \\
\hline (Adjusted residual) & $(-0.2)$ & $(16.9)$ & $(-12.5)$ & $(5.4)$ & $(-5.1)$ & \\
\hline Non-contextual problem & 932 & 273 & 1284 & 667 & 405 & 3561 \\
\hline (Percentage) & $(26.2 \%)$ & $(7.7 \%)$ & $(36.1 \%)$ & $(18.7 \%)$ & $(11.4 \%)$ & $(100 \%)$ \\
\hline (Adjusted residual) & $(0.2)$ & $(-16.9)$ & $(12.5)$ & $(-5.4)$ & $(5.1)$ & \\
\hline Total & 1099 & 470 & 1356 & 848 & 436 & 4209 \\
\hline (Percentage) & $(26.1 \%)$ & $(11.2 \%)$ & $(32.3 \%)$ & $(20.1 \%)$ & $(10.4 \%)$ & $(100 \%)$ \\
\hline
\end{tabular}

\section{Differences in question formats of geometry among the five mathematics textbooks}

The chi-square test for independence was used to determine whether there is an association between question format and country. A chi-square test for independence indicated a significant association between question format and country $((\mathrm{df}=4)=630.32, \mathrm{p}<0.001)$. This seems to indicate that the percentage of open-ended questions is significantly different from the percentage of close-ended questions for the textbooks from the five countries. Table 3 shows that Mainland China and the USA had the higher percentages of open-ended questions $(z=16.3$ 
and $z=15.7$, respectively), and conversely, Finland and Singapore had the higher percentages of close-ended questions ( $z=10.1$ and $z=11.8$, respectively).

Table 3. Cross-tabulation of question format and country with adjusted residuals

\begin{tabular}{lcccccc}
\hline \multirow{2}{*}{ Question format } & \multicolumn{7}{c}{ Country } \\
\cline { 2 - 7 } & Finland & Mainland & Singapore & Taiwan & USA & Total \\
\hline Open-ended question & 54 & 150 & 29 & 98 & 140 & 471 \\
(Percentage) & $(11.5 \%)$ & $(31.8 \%)$ & $(6.2 \%)$ & $(20.8 \%)$ & $(29.7 \%)$ & $(100 \%)$ \\
(Adjusted residual) & $(-10.1)$ & $(16.3)$ & $(-11.8)$ & $(1.3)$ & $(15.7)$ & \\
\hline Close-ended question & 1408 & 320 & 1327 & 750 & 296 & 4101 \\
(Percentage) & $(34.3 \%)$ & $(7.8 \%)$ & $(32.4 \%)$ & $(18.3 \%)$ & $(7.2 \%)$ & $(100 \%)$ \\
(Adjusted residual) & $(10.1)$ & $(-16.3)$ & $(11.8)$ & $(-1.3)$ & $(-15.7)$ & \\
\hline Total & 1462 & 470 & 1356 & 848 & 436 & 4572 \\
(Percentage) & $(32.0 \%)$ & $(10.3 \%)$ & $(29.7 \%)$ & $(18.5 \%)$ & $(9.5 \%)$ & $(100 \%)$ \\
\hline
\end{tabular}

The relationships between the scores of TIMSS-4 geometry, TIMSS- 8 geometry, PISA space and shape and the frequencies of representation form, problem type, and question format

Correlation analysis was performed to explore the relationships between some pairs of variables (e.g., the scores of TIMSS-4 and 8 geometry and PISA space and shape and the frequencies of verbal form, visual form, combined form, contextual problem, and open-ended question). As can be seen from Table 4, there was a strong positive relationship between visual form and TIMSS grade 4 geometry $(\mathrm{r}=0.502)$, followed by a moderate positive relationship between visual form and TIMSS grade 8 geometry $(r=0.386)$ and a weak positive relationship between visual form and PISA age 15 space and shape $(r=0.086)$. The results indicated that the strength of the positive relationships between visual form, TIMSS-4 geometry, TIMSS- 8 geometry, and PISA space and shape decreases as students advance to higher grades. Likewise, the strength of the positive relationships between combined form, TIMSS-4 geometry, TIMSS- 8 geometry, and PISA space and shape followed a similar pattern, indicating that the values of correlation coefficients decrease as students move from grade $4(\mathrm{r}=0.702$, large) to grade $8(\mathrm{r}=0.432$, medium) to age 15 ( $r=0.100$, small). Conversely, the strength of the positive relationships between contextual problem, TIMSS-4 geometry, TIMSS-8 geometry, and PISA space and shape reversed the pattern, that is, the values of correlation coefficients increase as students get older from grade $4(\mathrm{r}=0.149$, small) to grade $8(\mathrm{r}=$ 0.349 , medium) to age $15(\mathrm{r}=0.630$, large). Additionally, there were two negative correlations and one positive correlation between open-ended question, TIMSS-4 geometry, TIMSS-8 geometry, and PISA space and shape. Specifically, the results showed that there was a strong negative relationship between open-ended question and TIMSS-4 geometry $(\mathrm{r}=-0.619)$, with high frequency of open-ended question associated with a low score on TIMSS-4 geometry; a moderate negative relationship between open-ended question and TIMSS-8 geometry $(\mathrm{r}=$ 0.408), with high frequency of open-ended question associated with a low score on TIMSS-8 geometry; and a weak positive relationship between open-ended question and PISA space and shape $(r=0.004)$, with high frequency of open-ended question associated with a high score on PISA space and shape. Finally, the results showed that there were three positive correlations between verbal form, TIMSS-4 geometry, TIMSS-8 geometry, and PISA space and shape; however, there was no pattern evident in the relative strength of the correlations. In other words, there was a moderate positive relationship between verbal form and TIMSS-4 geometry $(r=0.474)$, a strong positive relationship between verbal form and TIMSS- 8 geometry $(\mathrm{r}=0.720)$, and a strong positive relationship between verbal form and PISA space and shape $(\mathrm{r}=0.502)$.

Table 4. Pearson correlation coefficients $(r)$ between each pair of variables listed

\begin{tabular}{lccccc}
\hline \multirow{2}{*}{ Test } & \multicolumn{4}{c}{ Representation form/ Problem type/Question format } \\
\cline { 2 - 6 } & $\begin{array}{c}\text { Verbal } \\
\text { form }\end{array}$ & $\begin{array}{c}\text { Visual } \\
\text { form }\end{array}$ & $\begin{array}{c}\text { Combined } \\
\text { form }\end{array}$ & $\begin{array}{c}\text { Contextual } \\
\text { problem }\end{array}$ & $\begin{array}{c}\text { Open-ended } \\
\text { question }\end{array}$ \\
\hline TIMSS grade 4 geometry & 0.474 & 0.502 & 0.702 & 0.149 & -0.619 \\
\hline TIMSS grade 8 geometry & 0.720 & 0.386 & 0.432 & 0.345 & -0.408 \\
\hline PISA age 15 space and shape & 0.502 & 0.086 & 0.100 & 0.630 & 0.004 \\
\hline
\end{tabular}




\section{DISCUSSION}

The results showed that there are significant differences in the representation forms among the five elementary school mathematics textbooks at a 0.001 level of significance. In particular, the Singapore textbooks have the highest percentage of the combined form. It appears that Singapore elementary school mathematics textbook series (MPHM) highly focuses on the visual form combined with other representation forms. Previous studies suggested that mathematics learning should put more emphasis on choosing different representations to appropriately help students make sense of the mathematics and further be able to have transformation ability among multiple representations, which can help students understand more deeply about mathematics content (Author et al., 2004; Cramer et al., 2002; NCTM, 2000; Rittle-Johnson \& Koedinger, 2005; Sood \& Jitendra, 2007). The high usage of a combined form including visual form and other different representation forms in Singapore elementary school mathematics textbooks may be the key factor that caused students from Singapore to perform well on international assessments.

The results also showed that there are significant differences between contextual and non-contextual problems among the five elementary school mathematics textbook series at a 0.001 level of significance. In particular, Mainland China has the highest percentage of contextual problems. Previous studies suggested that contextual problems in mathematics textbooks can promote students' mathematics learning, enhance students' conceptual understanding in mathematics (Author, 2006; Author et al., 2010; Griffin, 2004; Julie, 2013; Van De Walle, 2007; Zhu \& Fan, 2006), and create a learning environment to develop higher-order mathematical thinking (Gu, Huang, \& Marton, 2004). The new mathematics textbooks based on the ideas of reform of mathematics education in Mainland China seem to reflect the requirements of the international mathematics community, which encourages that contextual problems be integrated into mathematics teaching and assessment to improve students' performance in mathematics (Julie, 2013; NCTM, 2000; OECD, 2013; Zhu \& Fan, 2006). Mathematics textbook developers from Singapore and the USA may consider integrating more contextual problems related to geometry into mathematics textbooks.

The mathematics textbooks from Mainland China and the USA seem to include more open-ended geometrical questions. Previous studies suggested that open-ended questions provide students with more opportunities to solve higher-order thinking and challenging problems than closed-ended questions (Cai, 1995; Cai \& Ni, 2011; Zhu \& Fan, 2006). The study by Kwon, Park, and Park (2006) showed that the use of open-ended questions in mathematics classrooms can cultivate students' divergent thinking skills, including fluency, flexibility, and originality. Mathematics textbook developers from Finland and Singapore may consider including more openended questions related to geometry in mathematics textbooks.

The results of the correlation analysis showed that the strength of the positive relationships between visual form (combined form), TIMSS-4 geometry, TIIMSS-8 geometry, and PISA space and shape decreases as students advance to higher grades. Findings suggest that younger students may benefit more from a visual form and combined form. These findings support the findings of previous studies, indicating that the design of mathematics textbooks can affect students' learning outcomes (Cai, 2008; Cai \& Ni, 2011; Floden, 2002; Gonzalez et al., 2004; Schmidt, 2004; Schmidt et al., 2001; Stein, Remillard, \& Smith., 2007; Tarr et al., 2006; Törnroos, 2004). Since the combined form contains mostly a visual form, it is natural to conjecture that the visual form is the major one related to students' performance in mathematics.

The strength of the positive relationships between contextual problem, TIMSS- 4 geometry, TIIMSS-8 geometry, and PISA space and shape increases as students get older, indicating that the contextual problems concerning geometry in elementary school mathematics textbooks may be positively associated with students' future learning in reading and problem-solving abilities. One possible explanation related to this association could be that a strong positive relationship between contextual problems and PISA space and shape is due to the PISA test questions reflecting different aspects of the real world, which is similar to contextual problems in mathematics textbooks. Mainland China has the highest percentage of contextual problems in elementary school mathematics textbooks, which may explain Chinese students' best performance on PISA 2009 and 2012 tests (OECD, 2010, 2013). The high frequency of open-ended questions associated with low scores on TIMSS-4 geometry and TIMSS8 geometry may be attributable to the multiple-choice format of test questions on those two assessments. However, more studies with a larger sample size may be needed to confirm these findings.

\section{CONCLUDING REMARKS}

The present study makes three major contributions to the topic of geometry in elementary school mathematics textbooks. First, few studies have examined the differences in elementary school mathematics textbooks on the topic of geometry. The present study reports the differences in representation forms, problem types, and question formats among mathematics textbooks from five countries and the relationships between the scores of TIMSS- 4 
geometry, TIMSS-8 geometry, and PISA space and shape and the frequencies of representation form, problem type, and question format of mathematics textbooks from those five countries. These differences can serve as a benchmark for future textbook design or revision on geometry for different countries, especially as students from Finland, Mainland China, Singapore, and Taiwan perform at the top in mathematics on the TIMSS and PISA tests (Mullis, Martin, Gonzalez, \& Chrostowski, 2004; Mullis, Martin, Foy, \& Arora, 2012; OECD, 2010, 2013). Second, the results showed that there is a strong positive relationship between visual form and TIMSS-4 geometry, a moderate relationship between visual form and TIMSS-8 geometry, and a weak relationship between visual form and PISA space and shape. Findings suggest that visual form may play an important role in mathematics textbooks. These findings support the findings of previous studies that visual form can help students construct geometrical concepts and facilitate students' visualizations of geometrical objects (Arcavi, 2003; David \& Tomaz, 2012; Presmeg, 2006) and highlight the importance of visual form in mathematics teaching and learning (Bishop, 1991; Brenner, Herman, Ho, \& Zimmer, 1999; NCTM, 2000; River, 2010; Zimmermann \& Cunningham, 1991). Third, the trend of associations between the combined form and the three large-scale tests also decreases as students get older. This seems to highlight the importance of multiple representations in elementary school mathematics textbooks. These findings support the findings of previous studies, indicating that multiple representations may play a crucial role in mathematics education (Author et al., 2004; Cramer, Post, \& delMas, 2002; NCTM, 2000; Rittle-Johnson \& Koedinger, 2005; Sood \& Jitendra, 2007).

\section{ACKNOWLEDGEMENTS}

This paper is a part of a research project supported by the Ministry of Science and Technology, Taiwan with grant no. MOST 102-2511-S-415-002-MY3. Any opinions expressed here are those of the author and do not necessarily reflect the views of the Ministry of Science and Technology, Taiwan.

\section{REFERENCES}

Arcavi, A. (2003). The role of visual representations in the learning of mathematics. Educational Studies in Mathematics, 52, pp. 215-241.

Atiyah, M. (2001). Mathematics in the 20th century. American Mathematical Monthly, 108(7), pp. 654-666.

Author. (2006). Teaching Children Mathematics.

Author et al. (2004). Educational Studies.

Author et al. (2010). School Science and Mathematics.

Baker, D., Knipe, H., Cummings, E., Blair, C. and Gamson, D. (2010). One hundred years of elementary school mathematics in the United States: A content analysis and cognitive assessment of textbooks from 1900 to 2000. Journal for Research in Mathematics, 41(4), pp. 383-423.

Bishop, A. (1991). Mathematical enculturation: A cultural perspective on mathematics education. Dordrecht, The Netherlands: Kluwer.

Brenner, M.E., Herman, S., Ho, H.Z. and Zimmer, J.M. (1999). Cross-national comparison of representational competence. Journal for Research in Mathematics Education, 30(5), pp. 541-547.

Cai, J. (1995). A cognitive analysis of U.S. and Chinese students' mathematical performance on tasking involving computation, simple problem solving, and complex problem solving. Journal for Research in Mathematics Education (Monograph series 7). Reston, VA: NCTM.

Cai, J. (2008). Some highlights of the similarities and differences in intended, planned/implemented, and achieved curricula between China and the United States. In Z. Usiskin \& E. Willmore, ed., Mathematics curriculum in Pacific Rim countries-China, Japan, Korea, and Singapore. Charlotte, NC: Information Age.

Cai, J. and Ni, Y. (2011). Investigating curricular effect on the teaching and learning of mathematics in a cultural context: Theoretical and methodological considerations. International Journal of Educational Research, 50(2), pp. 6570.

Cai, J., Wang, N., Moyer, J.C., Wang, C. and Nie, B. (2011). Longitudinal investigation of the curricular effect: An analysis of student learning outcomes from the LieCal Project in the United States. International Journal of Educational Research, 50(2), pp. 117-136.

Chen, C. (2008). No gifted classes, cherish each child's education in Finland [in Chinese]. Taipei, Taiwan: Trojan.

Cramer, K.A., Post, T.R. and delMas, R.C. (2002). Initial fraction learning by fourth- and fifth-grade students: A comparison for the effects of using commercial curricula with the effects of using the rational number project curriculum. Journal for Research in Mathematics Education, 33(2), pp. 111-144.

Chavez, O. (2003). From the textbook to the enacted curriculum: Textbook use in the middle school mathematics classroom. Unpublished doctoral dissertation, University of Missouri, Columbia. 
David, M.M. and Tomaz, V.S. (2012). The role of visual representations for structuring classroom mathematical activity. Educational Studies in Mathematics, 80(3), pp. 413-431.

Fan, L. (2013). Textbooks research as scientific research towards a common ground on issues and methods of research on mathematics textbooks. ZDM, 45, pp. 765-777.

Fan, L., Zhu, Y. and Miao, Z. (2013). Textbooks research in mathematics education: Development, status and direction. ZDM, 45, pp. 633-646.

Finnish National Board of Education. (2004). National core curriculum for basic education 2004. Retrieved from http://www.oph.fi/english/publications/2009/national_core_curricula_for_basic_education

Floden, R.E. (2002). The measurement of opportunity to learn. In A. C. Porter \& A. Gamoran, ed., Methodological advances in cross-national surveys of educational achievement (pp. 229-266). Washington, DC: National Academy Press.

Fong, H.K., Ramakrishnan, C. and Gan, K.S. (2005). Maths 1A to 6B. Singapore: Federal - Marshall Cavendish Education.

Gonzales, P., Guzmán, J.C., Partelow, L., Pahlke, E., Jocelyn, L., Kastberg, D. and Williams, T. (2004). Highlights from the Trends in International Mathematics and Science Study (TIMSS) 2003. Washington, DC: U.S. Department of Education, National Center for Education Statistics.

Griffin, C.C. and Jitendra, A.K. (2009). Word problem-solving instruction in inclusive third-grade mathematics classrooms. The Journal of Educational Research, 102, pp. 187-201.

Griffin, S. (2004). Building number sense with number words: A mathematics program for young children. Early Childhood Research Quarterly, 19, pp. 173-180.

Gu, L., Huang, R. and Marton, F. (2004). Teaching with variation: An effective way of mathematics teaching in China. In L. Fan, N. Y. Wong, J. Cai, \& S. Li, ed., How Chinese learn mathematics: Perspectives from insiders (pp. 309345). Singapore: World Scientific.

Hiebert, J., Gallimore, R., Garnier, H., Givvin, K.B., Hollingsworth, H. and Jacobs, J. (2003). Teaching mathematics in seven countries: Results from the TIMSS 1999 video study. Washington, DC: U.S. Department of Education, National Center for Education Statistics.

Hong, D.S. and Choi, K.M. (2014). A comparison of Korean and American secondary school textbooks: The case of quadratic equations. Educational Studies in Mathematics, 85(2), pp. 241-263.

Ji, H. (2004). Do PEP school textbooks still monopolize the market? Information Times, 1. Retrieved from http://big5.xinhuanet.com/gate/big5/news.xinhuanet.com/book/2004-03/02/content_13 40202.htm

Julie, C. (2013). The stability of learners' choices for real-life situations to be used in mathematics. International Journal of Mathematical Education in Science and Technology, 44(2), pp. 196-203.

Kang Hsuan Educational Publishing Group (Ed.) (2009). KH middle school mathematics textbooks. Taipei: Kang Hsuan Educational Publishing Group.

Kwon, O.N., Park, J.S. and Park, J.Y. (2006). Cultivating divergent thinking in mathematics through an openended approach. Asian Pacific Education Review, 7(1), pp. 51-61.

Ma, J.S. and Tan, J. (2008). Early 21st century curriculum reform in China market forces [in Chinese]. Bulletin of Educational Materials, 36, pp. 47-62.

Ministry of Education in Singapore. (2001). Primary mathematics syllabus. Singapore: Curriculum Planning and Development Division Ministry of Education. Retrieved November 20, 2010, from the Ministry of Education database: http://www.moe.gov.sg/cpdd/doc/Maths_LowSec.pdf

Ministry of Education in Taiwan. (2008). Nine-year-integrated mathematics curriculum standards for national schools from grade 1 to 9 in Taiwan [in Chinese]. Taipei, Taiwan: Author.

Mullis, I.V.S., Martin, M.O., Gonzalez, E.J. and Chrostowski, S.J. (2004). TIMSS 2003 international mathematics report: Findings from IE A's Trends in International Mathematics and Science Study at the fourth and eighth grades. Chestnut Hill, MA: Boston College, TIMSS \& PIRLS International Study Center.

Mullis, I.V.S., Martin, M.O., Foy, P. and Arora, A. (2012). The TIMSS 2011 international results in mathematics. Chestnut Hill, MA: TIMSS \& PIRLS International Study Center, Boston College.

National Council of Teachers of Mathematics. (1989). Curriculum and evaluation standards for school mathematics. Reston, VA: Author.

National Council of Teachers of Mathematics. (2000). Principles and standards for school mathematics. Reston, VA: Author.

Organization for Economic Co-operation \& Development (OECD). (2010). Pisa 2009 results: What students know and can do: Student performance in reading, mathematics, and science (Vol. I). Paris: Author.

Organization for Economic Co-operation \& Development (OECD). (2013). Pisa 2012 results: What students know and can do: Student performance in mathematics, reading and science (Vol. I). Paris: Author.

Presmeg, N. (2006). Research on visualization in learning and teaching mathematics. In A. Gutierrez \& P. Boero, ed., Handbook of research on the psychology of mathematics education: Past, present, and future (pp. 205-236). Rotterdam, The Netherlands: Sense Publishers. 
Reys, B.J. and Reys, R.E. (2006). The development and publication of elementary mathematics textbooks: Let the Buyer Beware!. Phi Delta Kappan, 87(5), pp. 377-384.

Reys, B.J., Reys, R.E. and Chavez, O. (2004). Why mathematics textbooks matter. Educational Leadership, 61(5), pp. 61-66.

Reys, B.J, Reys, R.E. and Rubenstein, R. (2010). Mathematics curriculum: Issue, trends, and future direction. Seventy-second Yearbook. Reston, VA: NCTM.

Rikala, S., Sintonen, A., Uus-Leponiemi, T., Ilmavirta, R. and Sieppe, H. (2006). Laskutaito [in English], grade 1 to grade 6. Helsinki, Finland: WSOY Oppimateriaalit Oy.

Rittle-Johnson, B. and Koedinger, K.R. (2005). Designing knowledge scaffolds to support mathematical problem solving. Cognition and Instruction, 23, pp. 313-349.

River, F. (2010). There is more to mathematics than symbols. Mathematics Teaching, 218, pp. $42-47$.

Schoen, H.L., Ziebarth, S.W., Hirsch, C.R. and BrckaLorenz, A. (2010). A 5-year study of the first edition of the CorePlus Mathematics Curriculum. Charlotte, NC: Information Age.

Schmidt, W.H. (2004). A vision for mathematics. Educational Leadership, 61(5), pp. 6-11.

Schmidt, W.H., Wang, H.C., McKnight, C.C. and Curtis, C. (2005). Curriculum coherence: An examination of U.S. mathematics and science content standards from an international perspective. Journal of Curriculum Studies, 37(5), pp. 525-559.

Schmidt, W.H., Mcknight, C.C., Houang, R.T., Wang, H., Wiley, D.E., Cogan, L.S. and Wolfe, R.G. (2001). Why schools matter: A cross-national comparison of curriculum and learning. San Francisco: Jossey-Bass.

Sood, S. and Jitendra, A.K. (2007). A comparative analysis of number sense instruction in reform-based and traditional mathematics textbooks. The Journal of Special Education, 41(3), pp. 145-157.

Stein, M.K., Remillard, J. and Smith, M.S. (2007). How curriculum influences student learning. In F. K. Lester, Jr., ed., Second handbook of research on mathematics teaching and learning (pp. 319-369). Charlotte, NC: Information Age.

Stigler, J.W. and Hiebert, J. (2004). Improving mathematics teaching. Educational Leadership, 61(5), pp. 12-17.

Tarr, J., Chavez, O., Reys, R. and Reys, B. (2006). From the written to enacted curricula: Intermediary role of middle school mathematics in shaping students' opportunity to learn. School Science and Mathematics, 106, pp. 191201.

Törnroos, J. (2004). Mathematics textbooks, opportunity to learn and achievement. ICME-10M, Discussion Group 14. Copenhagen, Denmark.

Usiskin, Z. and Willmore, E. (Eds.). (2008). Mathematics curriculum in Pacific Rim countries-China, Japan, Korea, and Singapore. Charlotte, NC: Information Age.

Van De Walle, J.A. (2007). Elementary and middle school mathematics. 6th ed. New York: Longman.

Zhu, Y. and Fan, L. (2006). Focus on the representation of problem types in intended curriculum: A comparison of selected mathematics textbooks from Mainland China and the United States. International Journal of Science and Mathematics Education, 4, pp. 609-626.

Zimmerman, W. and Cunningham, S. (Eds.). (1991). Editors introduction: What is mathematical visualization? In W. Zimmerman and S. Cunningham, ed., Visualization in teaching and learning mathematics. MAA Notes Number 19 (pp. 1-7). Washington DC: Mathematical Association of America. 